\title{
EDITORIAL
}

\section{DESAFÍOS FUTUROS}

La Revista Chilena de Radiología comenzó su trabajo hace 20 años como órgano oficial de divulgación científica de nuestra especialidad y ha sido, sin duda, el mejor medio para difundir la las iniciativas técnicas, científicas y gremiales de nuestra Sociedad.

Durante estos años hemos visto la mejoría paulatina en la calidad y visibilidad de los trabajos publicados, los cuales actualmente son vistos no sólo en Chile sino también en el resto de Latinoamérica, gracias al trabajo que durante años han realizado editores, comités, revisores y por supuesto, los investigadores en los diferente centros del país.

Nos enfrentamos ahora a una nueva etapa, donde la calidad y cantidad de artículos se mantienen como un desafío para dar cuerpo a nuestra revista número a número, y donde los desafíos nuevos, irán apareciendo de la mano de la profesionalización del proceso editorial.

Para esto nos encontramos trabajando en el diseño de un nuevo Comité Editorial, con mayor número de integrantes, que permita representar las distintas áreas del conocimiento y los diferentes centros asistenciales, públicos y privados, a lo largo del país. Una prestigiosa casa editorial, se hará cargo de asistirnos en el trabajo, aportando su tecnología, metodología y obviamente su trayectoria. Este camino ya ha sido emprendido con éxito por otras revistas chilenas, como la revista Médica de Chile, la Revista Chilena de Infectología y la Revista Chilena de Pediatría.

¿Hacia dónde van nuestras revistas?, a ser consideradas por la National Library of Medicine de Estados Unidos para poder ser incluidas en el catálogo MEDLINE. ¿Qué necesita nuestra revista? Necesita prolijidad del proceso editorial, para la lo cual la profesionalización ligada a una empresa debiera ayudarnos. Requiere además un alto nivel técnico de las publicaciones manteniendo un flujo de artículos capaz de generar repercusión a nivel internacional, efecto que se logra aumentando la representación de trabajos originales y de artículos de revisión, sin perder norte de nuestra revista, como ha sido el apoyo al radiólogo general de habla hispana.

El desarrollo que ha tenido nuestro país en nuestra especialidad ha sido significativo en los últimos años, especialmente si consideramos el aumento del número de especialistas, su mayor preparación tanto en Chile como en el extranjero y la incorporación creciente de tecnología de punta tanto en los centros públicos como privados. Esto ha hecho que contraigamos una deuda con el país en relación a la producción científica e innovación tecnológica que somos capaces de hacer y los cambios en conductas y protocolos que somos capaces de generar en la interacción con los otros especialistas.

Si al futuro nos referimos, nadie puede predecir en verdad qué va a suceder. Sólo nos queda entonces trabajar, para mejorar y disminuir así la brecha entre lo que somos ahora y lo que debiéramos ser.

Dr. Marcelo Gálvez

Editor Científico 